\title{
Produção de matéria seca de Stylosanthes capitata submetido à adubação fosfatada em solos com diferentes texturas
}

\section{Production of dry matter of Stylosanthes capitata submitted to phosphorus in soil with different textures}

\author{
Auro Akio Otsubo ${ }^{*}$; Osmar Rodrigues Brito ${ }^{2}$; Jenniffer Aparecida Schnitzer ${ }^{3}$; \\ Victor Hugo Nakase Otsubo ${ }^{4}$
}

\section{Resumo}

\begin{abstract}
A baixa disponibilidade de fósforo (P) está entre os fatores que limitam o desenvolvimento do estilosante. Somente com manejo adequado que vise aumentar a liberação do fósforo no solo se consegue altos rendimentos desta leguminosa. O trabalho foi desenvolvido em casa de vegetação na Universidade Estadual de Londrina (UEL), com o objetivo de avaliar o efeito de doses de P na produção de matéria seca de Stylosanthes capitata em solos com texturas arenosa (Latossolo Vermelho-Amarelo Distrófico - LVAd) e argilosa (Latossolo Vermelho Eutroférrico - Lvef). O delineamento experimental empregado foi inteiramente casualizado com quatro repetições, em um esquema fatorial $2 \times 5 \times 2$, em que os fatores foram dois tipos de solos, cinco doses de fósforo $\left(0 ; 40 ; 80 ; 120\right.$ e $160 \mathrm{~kg} \mathrm{ha}^{-1} \mathrm{de}_{2} \mathrm{O}_{5}$ ) e dois cortes. Para semeadura foram utilizadas sementes de Stylosanthes capitata. Os cortes da parte aérea foram realizados aos 60 e 105 dias após a semeadura. Independentemente da textura e do corte, a adubação fosfatada aumentou a produção de matéria seca da parte aérea do estilosantes. A maior produção foi obtida no segundo corte e no solo de textura arenosa. Com o aumento das doses aumenta-se o conteúdo de fósforo na matéria seca produzida, melhorando a sua qualidade nutricional para alimentação dos animais. As máximas produções de matéria seca (2,39 g/planta no solo arenoso e 1,36 g/planta no solo argiloso) foram obtidas com as doses de 102,69 e 113,25 kg ha-1 de $\mathrm{P}_{2} \mathrm{O}_{5}$, respectivamente.
\end{abstract}

Palavras-chave: Leguminosa forrageira, integração lavoura-pecuária

\begin{abstract}
The low availability of phosphorus is among the factors that limit the development of the Stylosanthes. Only with the appropriate management aiming to increase the phosphorus liberation in the soil we can provide the increase in yield of this leguminous plant. The study was conducted in a greenhouse at the University of Londrina (UEL), the objective was to evaluate the effect of P shoots of Stylosanthes capitata in soil with sandy texture (Typical Yellow Dystropic - LVAd) and clay (Typical Eutrophic Lvef). The experimental design used was completely randomized with four replications in a $2 \times 5 \times 2$ factorial design, in which the factors were two soil types, five shots of phosphorus $(0,40,80,120$ and $160 \mathrm{~kg} \mathrm{ha}^{-1}$ of $\mathrm{P}_{2} \mathrm{O}_{5}$ ) and two cuts. For the sowing, seeds of Stylosanthes capitata were used. The aerial part's cuts were made at 60 and 105 days after sowing. Regardless of the texture and cut, the phosphated fertilization increased the dry matter production of Stylosanthes' aerial part, and the maximum yield was obtained with a shot of $105 \mathrm{~kg} \mathrm{ha}^{-1} \mathrm{P}_{2} \mathrm{O}_{5}$. Among the soils the biggest production was obtained
\end{abstract}

\footnotetext{
1 Eng ${ }^{\circ}$ Agr ${ }^{\circ}$, MSc. Doutorando. Pesquisador da Embrapa Agropecuária Oeste. Rod. BR 163, km 253,6, C P 661, Dourados, MS. CEP: 79.804-970. E-mail: auro.ao@hotmail.com

2 Prof. do Dept $^{\mathrm{o}}$ de Agronomia da Universidade Estadual de Londrina, UEL, Londrina, PR. E-mail: osmar@uel.br

3 Bióloga. Doutoranda em Agronomia. UEL, Londrina, PR. Bolsista CNPq. E-mail: je_uel@yahoo.com.br

4 Acadêmico de Agronomia da UEL. Londrina, PR. E-mail: sobraldo@,msn.com

*Autor para correspondência
} 
in the second cut and soil of sandy texture. With the increase of the doses, the phosphorus content increases in dry matter yield, improving their nutritional quality for animal feed. The maximum dry matter production $(2.39 \mathrm{~g} /$ plant in sandy soil and $1.36 \mathrm{~g} /$ plant in clay soil) were obtained with doses of 102.69 and $113.25 \mathrm{~kg} \mathrm{ha}^{-1} \mathrm{P}_{2} \mathrm{O}_{5}$, respectively.

Key words: Forager legume, agriculture-farmers integration

\section{Introdução}

O Brasil é o maior produtor de carne bovina do mundo, sendo que em 2008, exportou o equivalente a $25 \%$ do total mundial. Além disso, detém o maior rebanho comercial do mundo com cerca de 175 milhões de cabeça, sendo superado apenas pela Índia, cujo rebanho é formado por cerca de 282 milhões de cabeças (IMEA, 2009). De acordo com Macedo, Kichel e Zimmer (2000) grande parte das pastagens cultivadas do Brasil Central (80\%), que responde por $55 \%$ da produção nacional, encontram-se em algum estádio de degradação. Para Kichel e Kichel (2002), a degradação das pastagens constitui-se em um dos principais problemas da pecuária brasileira, afetando diretamente a sustentabilidade do sistema, através da perda de vigor e de produtividade das pastagens afetando a produção e o desempenho animal, além de culminar na degradação dos solos e outros recursos naturais.

Para Macedo, Kichel e Zimmer (2000), a degradação das pastagens pode ser atribuída a vários fatores dentre as quais pode-se destacar a escolha incorreta da espécie forrageira, a má formação inicial, a ausência ou inadequação das adubações de manutenção (WERNER, 1984; OLIVEIRA et al., 1997) além de práticas inadequadas de manejo do pasto. A degradação das pastagens precisa ser revertida para se garantir a viabilidade econômica da atividade, segundo os autores isto poderá ser obtido mediante a escolha de espécies forrageiras adaptadas às condições edafoclimáticas das diferentes regiões produtoras associada a um programa adequado de manejo.

Na maioria das situações, as pastagens brasileiras são formadas por gramíneas do gênero Brachiaria que apresentam baixa produtividade e baixa taxa de lotação (VALENTIM; ANDRADE, 2004).
Uma das alternativas para aumentar e melhorar a qualidade das forragens, segundo Mesquita et al. (2002), seria a utilização do consórcio de gramíneas com leguminosas tropicais. Este tipo de associação ou consórcio, segundo Shelton, Franzel e Peters (2005), resolveriam dois problemas: os baixos teores de nitrogênio do solo, pois as leguminosas forrageiras apresentam capacidade de fixar biologicamente o nitrogênio atmosférico e melhoraria a qualidade e quantidade de proteína produzida via pastagens. Uma outra característica importante das forrageiras tropicais está relacionada à concentração de $\mathrm{P}$ na planta que serve como indicativo de seu valor nutricional. De acordo com Noller, Nascimento Júnior e Queiroz, (1996) concentrações de $\mathrm{P}$ abaixo $0,18 \%$ na matéria seca da forrageira indicam a necessidade de suplementação mineral para os animais. No caso de pastagens formadas com Brachiaria brizantha, Passos et al. (1997) verificaram que a aplicação de diferentes fontes de fósforo não proporcionou concentrações de $\mathrm{P}$ na MS suficientes para atender as exigências mínimas de bovinos em pastejo, uma vez que nesta situação os animais tendem a selecionar plantas ou partes da planta com maiores concentrações de P (JONES; BETTERIDGE, 1994). De acordo com Russelle (1997), essa preferência pode estar relacionada ao aroma, textura ou composição das plantas bem nutridas em $\mathrm{P}$.

Entre as leguminosas forrageiras tropicais, o estilosantes tem recebido maior atenção dos pesquisadores e pecuaristas devido a sua alta qualidade nutricional e palatabilidade. Recentes resultados de pesquisa têm comprovado o desempenho agronômico e zootécnico da cultivar "Estilosantes Campo Grande", para utilização em consórcio com gramíneas ou em cultivo solteiro 
(GARCIA et al., 2008; PAULINO et al., 2006; MELLO; SILVA; SANTOS, 2010; ANDRADE; ASSIS; SALES, 2010; MOURA et al., 2011).

Em estudos realizados por Fernandes et al. (2005), o consórcio dos "estilosantes Campo Grande" com Brachiaria decumbens apresentou teores de proteína bruta superiores à B. decumbens solteira, cujos teores variaram de $17,4 \%$ no período das águas a $43,8 \%$ no período das secas. O desempenho animal tem comprovado a boa adaptação e o alto valor nutritivo dessa leguminosa. Em trabalhos realizados por Schunke e Silva (2003), a produção de carne aumentou de 9 a 34\% nos consórcios dessa leguminosa com brachiárias quando comparados com cultivos solteiros da gramínea. Esses autores salientaram ainda, que o uso correto da pastagem consorciada possibilita maiores ganhos, principalmente quando se utiliza os pastejo rotacionado ou em sistemas de manejo de integração lavourapecuária, que além da carne, se produz grãos que podem ser comercializados separadamente ou utilizados no arraçoamento dos animais (PETEAN et al., 2009).

O "Estilosantes Campo Grande" é comercializado como uma mistura de sementes de $S$. capitata e $S$. macrocephala, na proporção de 80 e $20 \%$, respectivamente. O S. capitata tem hábito de crescimento ereto, podendo atingir até $1,5 \mathrm{~m}$ de altura enquanto a $S$. macrocephala é de porte prostrado podendo atingir a mesma altura do anterior (EMBRAPA, 2007).

Se a textura é um bom indicador da qualidade e produtividade dos solos (COX; LINS, 1984; SANTOS et al., 2008) para Embrapa (2007) o estilosantes Campo Grande se adapta melhor aos solos de textura arenosa (teores de argila inferiores a 15\%). Nos solos argilosos normalmente é baixa a sobrevivência das plântulas originadas da ressemeadura natural, resultando em baixa persistência do consórcio, uma vez que a maior fertilidade natural destes solos proporciona maior e mais rápido desenvolvimento da gramínea, que passa a competir com o estilosantes, reduzindo sua persistência. Outros fatores associados aos solos argilosos e que prejudicam o desenvolvimento do $S$. capitata seriam a baixa permeabilidade do solo, a drenagem deficiente e a ocorrência de encharcamentos, como já foi confirmado em estudos realizados por Andrade e Valentim (2008) que observaram a intolerância dessa leguminosa ao alagamento temporário.

Entre os diversos nutrientes exigidos para a adequada nutrição do estilosantes, o fósforo merece destaque especial, uma vez que junto com o nitrogênio são os nutrientes que promovem os maiores incrementos na produtividade das culturas exploradas economicamente em solos tropicais, e, segundo Paulino et al. (2006) é o mais limitante para o Stylosanthes capitata. De acordo com diversos pesquisadores, entre eles Goedert e Souza (1986), Raij, (1991), Fardeau, (1996), Novais e Smyth (1999) o fósforo é considerado o nutriente que ocorre em menor disponibilidade nos solos brasileiros.

Este trabalho foi conduzido com o objetivo de avaliar a produção de matéria seca da parte aérea do Stylosanthes capitata, quando submetido a diferentes doses de fósforo em solos de textura arenosa e argilosa.

\section{Material e Métodos}

O experimento foi conduzido em vasos, em ambiente de casa de vegetação na Universidade Estadual de Londrina (UEL), no município de

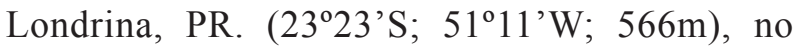
período de 15/08/2008 a 30/01/2009. Foram utilizadas amostras de terra coletadas da camada superficial $(0-20 \mathrm{~cm})$ de dois tipos de solos: um Latossolo Vermelho Eutroférrico, muito argiloso (argila=885 $\mathrm{g} \mathrm{kg}^{-1}$ ), do município de Londrina, PR e um Latossolo Vermelho-Amarelo Distrófico (LVAd), arenoso (areia $=710 \mathrm{~g} \mathrm{~kg}^{-1}$ ), do município de Jaguapitã, PR $\left(23^{\circ} 06^{\prime} \mathrm{S}, 51^{\circ} 31^{\prime} \mathrm{W}\right.$, 
610m) (SISTEMA..., 2006). A terra coletada foi passada em peneira com malha de $6,0 \mathrm{~mm}$ antes da transferência para os vasos. Os resultados das análises químicas da TFSA, realizadas antes da instalação do experimento encontram-se expostos na tabela 1 .

Tabela 1. Resultados das análises químicas da TFSA, realizadas antes da instalação do experimento.

\begin{tabular}{|c|c|c|c|c|c|c|c|}
\hline \multirow[t]{2}{*}{ Solos } & $\mathbf{p H}$ & $\mathbf{P}$ & $\mathbf{K}^{+}$ & $\mathrm{Ca}^{2+}$ & $\mathrm{Mg}^{2+}$ & $\mathbf{H}+\mathbf{A l}$ & $\mathbf{V}$ \\
\hline & $\mathrm{CaCl}_{2}$ & $\mathbf{m g ~ d m ^ { - 3 }}$ & -- & ------- & \multicolumn{2}{|c|}{$\mathrm{cmol}_{\mathrm{c}} \mathrm{dm}^{-3}$} & $\%$ \\
\hline$\overline{\text { Argiloso }}$ & 5,3 & 0,4 & 0,07 & 5,71 & 2,53 & 4,6 & 64 \\
\hline Arenoso & 3,8 & 3,3 & 0,14 & 0,77 & 0,49 & 8,4 & 14 \\
\hline
\end{tabular}

O delineamento experimental empregado foi o inteiramente casualizado (DIC), com quatro repetições. Os tratamentos resultaram do esquema fatorial $2 \times 5 \times 2$, em que os fatores foram dois tipos de solos (arenoso e argiloso), cinco doses de fósforo ( 0 ; 40; 80; 120 e $160 \mathrm{~kg} \mathrm{ha}^{-1}$ de $\mathrm{P}_{2} \mathrm{O}_{5}$ ) e duas épocas de corte da parte aérea (60 e 105 dias após a semeadura). Cada parcela experimental foi constituída por um vaso com capacidade para 3,0 kg de terra. Para evitar restrição nutricional, foi aplicada superficialmente uma solução contendo todos os nutrientes exceto fósforo, como indicado por Novais, Neves e Barros (1991). Para avaliar o efeito das doses de fósforo foi utilizado como fonte deste nutriente o fertilizante superfostato triplo aplicado de forma localizada. Para realizar a aplicação do fertilizante removeu-se de cada vaso uma camada de terra equivalente a 5,0 $\mathrm{cm}$. Procedeu-se a distribuição do adubo fosfatado, retornando aos vasos a terra retirada inicialmente. Esta metodologia de aplicação foi utilizada para simular a situação normalmente utilizada para instalação da cultura a campo.

Uma semana após o preparo e umedecimento dos vasos procedeu-se a semeadura distribuindose 15 sementes por vaso. Após a emergência fez-se um desbaste seletivo e de forma gradativa deixando apenas 4 plantas de $S$. capitata por vaso.

Durante o período experimental foi realizada a reposição diária da água evapotranspirada mediante pesagem dos vasos. Procurou-se manter a umidade próxima a $80 \%$ da capacidade máxima de retenção de água do solo.

Aos 60 e 105 dias da semeadura foram realizados os cortes da parte aérea do estilosantes a uma altura de 5,0 cm da superfície o solo, para avaliação da produção de matéria seca da parte aérea. O material vegetal colhido foi lavado e posteriormente seco em estufa mantida à temperatura de $60{ }^{\circ} \mathrm{C}$ até obtenção de massa constante. Depois de pesada, cada amostra foi moída e analisada quimicamente seguindo as metodologias descritas em Malavolta, Vitti e Oliveira (1997), para avaliação dos teores de P na matéria seca de tecidos vegetais. A determinação do fósforo foi realizada de acordo com a metodologia descrita por Miyazawa, Pavan e Bloch (1992).

A amostragem de solo para fins de avaliação da fertilidade foi realizada após o segundo corte, e a avaliação dos teores de P foi feita empregando a solução extratora Mehlich-1 (MIYAZAWA; PAVAN; BLOCH, 1992).

Os dados obtidos foram submetidos à análise de variância e as médias foram comparadas pelo teste de Tukey a 5\% ou ajustadas a equações de regressão.

\section{Resultados e Discussão}

As maiores produções de matéria seca de parte aérea do estilosantes foram obtidas no solo de textura arenosa, tanto no primeiro como no segundo corte (Tabela 2), assim como observaram Garcia et al. (2008) e Andrade, Assis e Sales (2010). 
Segundo Embrapa (2007), o melhor desempenho do estilosante ( $S$. capitata ou $S$. macrocephala) se dá em solos arenosos, principalmente naqueles que apresentam entre 15 e $35 \%$ de argila, como é o caso do solo arenoso utilizado neste estudo. Além disso, como destacam Andrade, Assis e Sales (2010) é baixa a sobrevivência das plântulas de estilosantes em solos argilosos, principalmente devido à menor drenagem verificada nestes solos. Nesta situação há comprometimento da consorciação com gramíneas, normalmente mais rústicas e persistentes. Ressaltase que neste trabalho não foi verificada a morte de nenhumas das plantas selecionadas para condução do experimento quando se utilizou o solo argiloso.

Tabela 2. Produção de matéria seca da parte aérea de Stylosanthes capitata $\left(\mathrm{g}\right.$ planta $\left.{ }^{-1}\right)$, em função dos cortes e do tipo de solo. Londrina, PR. 2009.

\begin{tabular}{llc}
\hline Cortes & Arenoso & Argiloso \\
\hline Primeiro & $1,60 \mathrm{Ba}$ & $0,90 \mathrm{Bb}$ \\
Segundo & $2,49 \mathrm{Aa}$ & $1,49 \mathrm{Ab}$ \\
\hline
\end{tabular}

Médias seguidas da mesma letra maiúscula nas colunas e minúsculas nas linhas não diferem entre si, pelo teste de Tukey a 5\% de probabilidade.
As produções de matéria seca da parte aérea, obtidas no segundo corte, foram sempre maiores que aquelas observadas no primeiro, independentemente do tipo de solo (Tabela 2). No primeiro corte, a maior produção $\left(1,53 \mathrm{~g} \mathrm{pl}^{-1}\right)$ foi obtida com a dose de $113,57 \mathrm{~kg} \mathrm{ha}^{-1} \mathrm{de}$ $\mathrm{P}_{2} \mathrm{O}_{5}$. Já no segundo, a maior produção $\left(2,48 \mathrm{~g} \mathrm{pl}^{-1}\right)$ foi obtida com a dose de $110 \mathrm{~kg} \mathrm{ha}^{-1}$ de $\mathrm{P}_{2} \mathrm{O}_{5}$ (Figura 1). Estes resultados estão de acordo com aqueles obtidos por Moura et al. (2011) que verificaram aumento linear na produção de matéria seca de $S$. capitata em função do número de rebrotes ou cortes. Segundo os autores, esse efeito ocorre devido a redução da relação folha/haste que se verifica com o aumento da idade das plantas do estilosantes.

As doses de fósforo também influenciaram de forma significativa a produção de matéria seca da parte aérea do estilosante (Figura 2), o que corrobora com os resultados observados por Paulino et al. (2006), que consideram o fósforo como o elemento químico que mais limita o crescimento e desenvolvimento desta leguminosa. No solo arenoso e no argiloso, as máximas produções de matéria seca $(2,39$ e 1,36 g/ planta) foram obtidas com as doses de 102,69 e 113,25 $\mathrm{kg} \mathrm{ha}^{-1}$ de $\mathrm{P}_{2} \mathrm{O}_{5}$, respectivamente.

Figura 1. Produção de matéria seca da parte aérea de Stylosanthes capitata em função dos cortes e doses de fósforo. Média de dois solos. Londrina, PR. 2009.

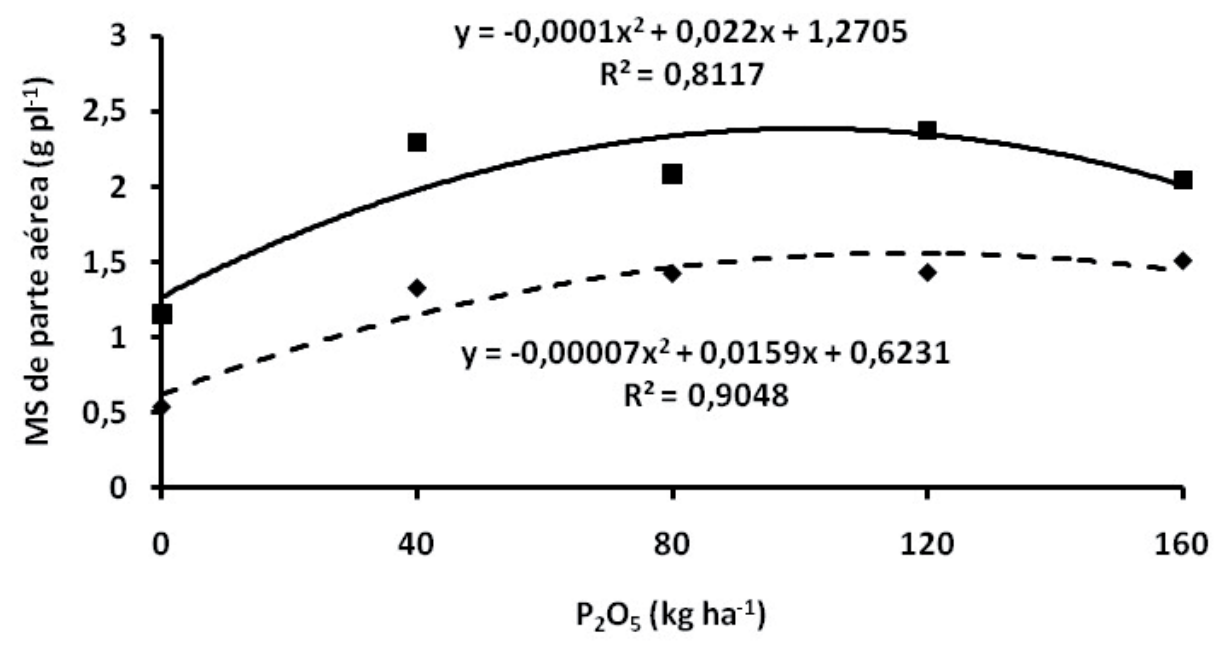

- Primeiro corte $\mathbf{\square}$ Segundo corte 
Figura 2. Produção de matéria seca da parte aérea de Stylosanthes capitata em função de doses de fósforo. Média de dois cortes. Londrina, PR. 2009.

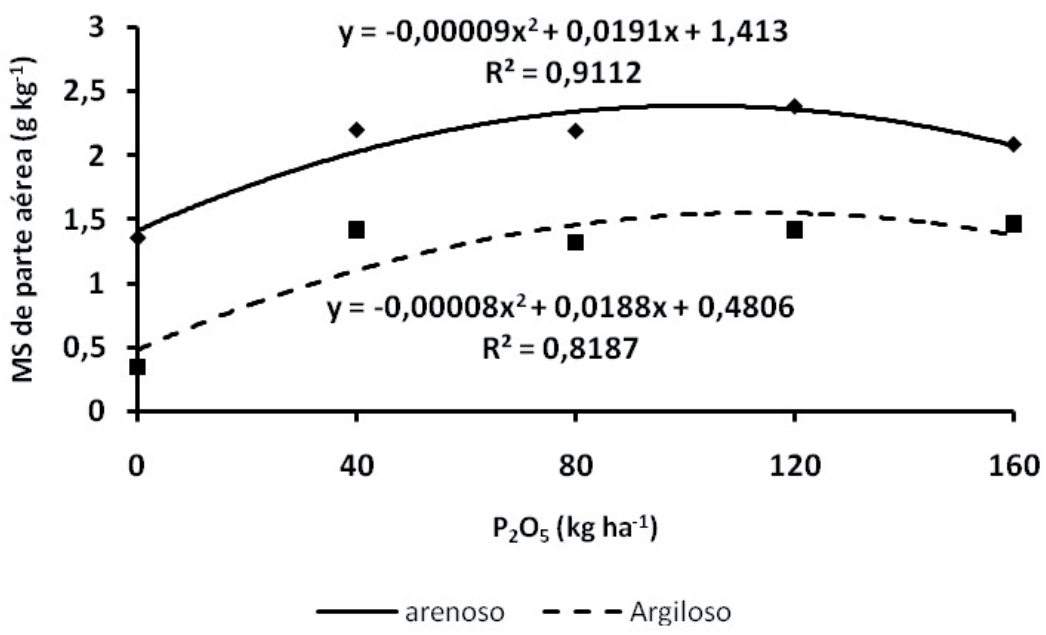

Aadubação fosfatada resultou sempre no aumento dos teores de fósforo disponível, principalmente no solo arenoso (Figura 3). Estes resultados que estão associados à menor capacidade de adsorção de $\mathrm{P}$ deste solo, como indicam as observações feitas por diferentes autores como Valladares, Pereira e Dos Anjos (2003) e Rolim Neto et al. (2004). De acordo com as sugestões em Embrapa (2007) para a cultura do estilosantes, os teores iniciais de fósforo dos solos utilizados nesse trabalho podem ser classificados como muito baixo e baixo, para o solo argiloso e arenoso, respectivamente. As doses que determinaram as produções máximas de matéria seca da parte aérea, resultaram em teores no solo de 23 e $6,9 \mathrm{mg} \mathrm{dm}^{-3}$ nos solos arenoso e argiloso, respectivamente. No caso do solo arenoso o valor observado ficou acima do nível crítico de P estabelecido para cultura que é de 9,0 mg dm-3. De acordo com os mesmos autores ainda não foi estabelecido o nível crítico de $\mathrm{P}$ dos solos argilosos, utilizados no cultivo de estilosantes.

Figura 3. Teores de fósforo no solo cultivado com Stylosanthes capitata em função das doses de $\mathrm{P}_{2} \mathrm{O}_{5}$. Londrina, PR. 2009.

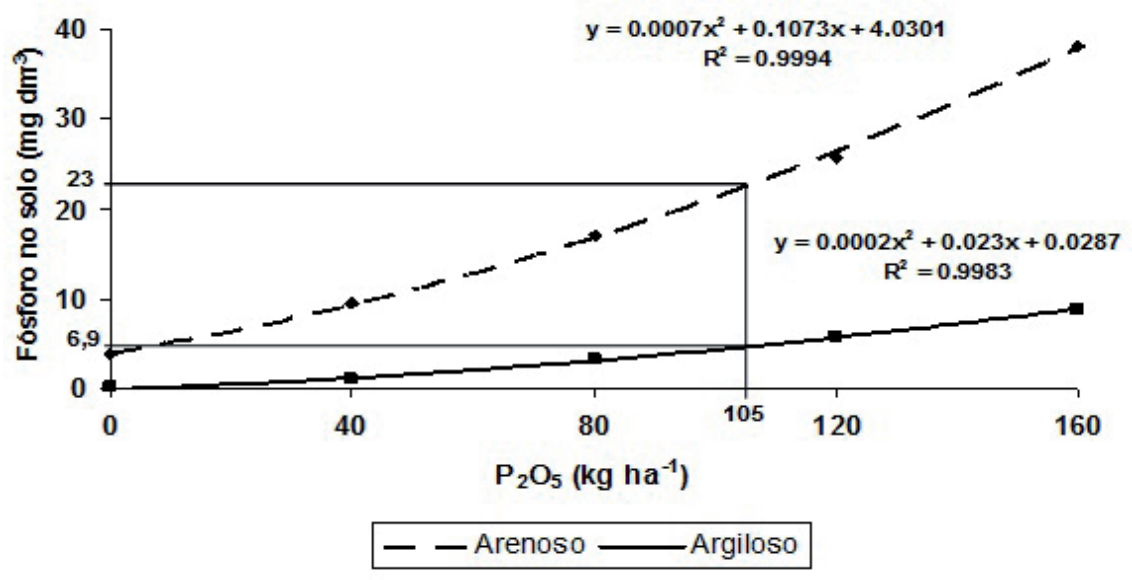


O conteúdo de fósforo na matéria seca variou com as doses de $\mathrm{P}$ ajustando-se ao modelo quadrático, sendo que o ponto de máximo $(9,8 \mathrm{mg}$ $\left.\mathrm{pl}^{-1}\right)$ foi obtido com a dose de $135 \mathrm{~kg} \mathrm{ha}^{-1}$ de $\mathrm{P}_{2} \mathrm{O}_{5}$ (Figura 4). Como se pode observar nesta figura a maior disponibilidade do fósforo no solo arenoso refletiu diretamente no seu conteúdo na matéria seca da parte aérea do estilosante. Apesar das diferenças entre solos, não foram observadas diferenças de conteúdo de $\mathrm{P}$ da matéria seca entre os cortes. Os maiores conteúdos observados na matéria seca da parte aérea do estilosantes cultivado no solo arenoso (Tabela 3) está diretamente relacionado aos maiores teores de P verificado nesse solo (Tabela 2). Essa estreita relação entre o teor do nutriente no solo e os teores e conteúdos do nutriente na matéria seca da planta também foi observado por Rodrigues (2009).

Tabela 3. Conteúdo de fósforo na matéria seca da parte aérea de estilosantes $\left(\mathrm{mg} \mathrm{pl}^{-1}\right)$, em função dos cortes e tipos de solo.

\begin{tabular}{llc}
\hline Cortes & Arenoso & Argiloso \\
\hline Primeiro & $10,42 \mathrm{Aa}$ & $4,47 \mathrm{Ab}$ \\
Segundo & $11,16 \mathrm{Aa}$ & $5,09 \mathrm{Ab}$ \\
\hline
\end{tabular}

Médias seguidas de mesma letra maiúscula nas colunas e minúsculas nas linhas não diferem entre si, pelo teste de Tukey a $5 \%$ de probabilidade.

Figura 4. Conteúdo de fósforo na matéria seca de parte aérea de Stylosanthes capitata em função das doses de $\mathrm{P}_{2} \mathrm{O}_{5}$. Londrina, PR. 2009.

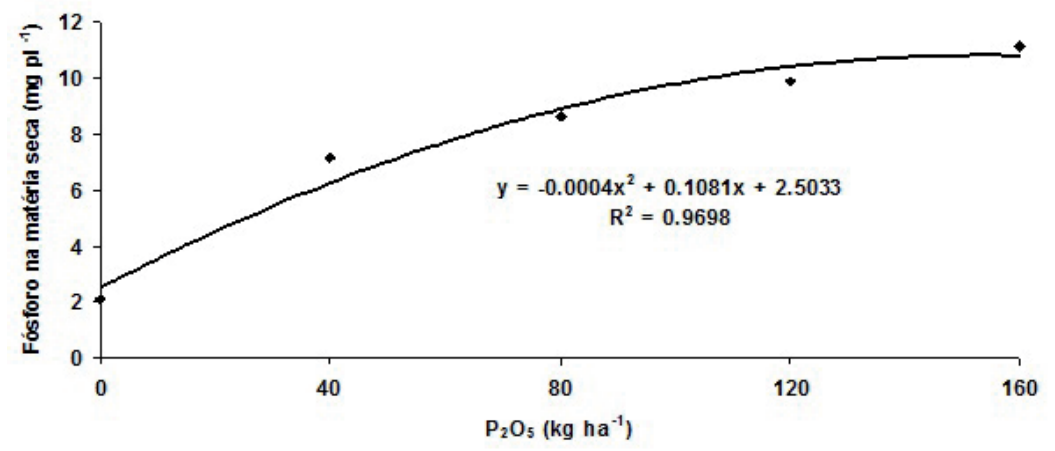

\section{Conclusões}

A produção de matéria seca do Stylosanthes capitata aumenta com as doses de fósforo independentemente da textura dos solos.

As máximas produções $(2,39 \mathrm{~g} /$ planta no solo arenoso e 1,36 g/planta no solo argiloso) foram obtidas com as doses de 102,69 e $113,25 \mathrm{~kg} \mathrm{ha}^{-1} \mathrm{de}$ $\mathrm{P}_{2} \mathrm{O}_{5}$, respectivamente.

Com o aumento das doses de fósforo há aumento do conteúdo deste nutriente na matéria seca produzida, melhorando a qualidade nutricional para alimentação dos animais.

\section{Referências}

ANDRADE, C. M. S. de; ASSIS, G. M. L. de; SALES, M. F. L. Estilosantes Campo Grande: leguminosa forrageira recomendada para solos arenosos do Acre. Rio Branco: Embrapa Acre, 2010. 12 p. (Embrapa Acre. Comunicado técnico, 55).

ANDRADE, C. M. S. de; VALENTIM, J. F. Desempenho agronômico do estilosantes campo grande no Acre. Rio Branco: Embrapa Acre, 2008. 35 p. (Embrapa Acre. Documentos, 111).

COX, F. R.; LINS, D. G. A phosphorus soil test interpretation for corn grown on acid soils varying in crystalline clay content. Comm. Soil Sci. Plant Anal., Nova York, v. 15, n. 12, p. 1481-1491, 1984.

EMPRESA BRASILEIRA DE PESQUISA AGROPECUÁRIA - EMBRAPA. Cultivo e uso do 
estilosantes-campo-grande Campo Grande, MS. Embrapa Gado de Corte, 2007. 11 p. (Embrapa Gado de Corte. Comunicado técnico, 105).

FARDEAU, J. C. Dynamics of phosphate in soils: an isotopic outlook. Fertility Research, Netherlands, v. 45, n. 2, p. 91-100, 1996.

FERNANDES, C. D.; GROF, B.; CHAKRABORTY, S.; VERNIGNASSI, J. R. Estilosantes Campo Grande in Brazil. A tropical forage legume succes story. In: INTERNATIONAL GRASSLAND CONGRESS, 20., 2005, Dublin. Proceedings... Dublin: Wageningen Academic, 2005. p. 330.

GARCIA, F. M.; BARBOSA, R. Z.; GIATTI JUNIOR, N. O.; VIEIRA, F. M. O uso de estilosantes Campo Grande em consórcio com braquiarinha (Brachiaria decumbens). Revista Científica Eletrônica de Agronomia, Garça, ano 7, n. 13, 2008.

GOEDERT, W. J.; SOUSA, D. M. G. Avaliação preliminar da eficiência de fosfatos com acidulação parcial. Revista Brasileira de Ciência do Solo, Viçosa, MG, v. 10, n. 1, p. 75-80, 1986.

INSTITUTO MATO-GROSSENSE DE ECONOMIA AGRÍCOLA - IMEA. Relatório estatístico da bovinocultura. jan. 2009. Disponível em : <http://www. famato.org.br/site/arquivos/0901_RMB.pdf.>. Acesso em: 10 ago. 2011.

JONES, R. J.; BETTERIDGE, K. Effect of superphosphate, or its components elements (phosphorus, sulfur, and calcium), on the grazing preference of steers on a tropical grass-legume pasture grown on a low phosphorus soil. Australian Journal of Experimental Agriculture, Melbourne, v. 34, n. 3, p. 349-353, 1994.

KICHEL, A. N.; KICHEL, A. G. Sistemas extensivos e intensivos de produção de carne custo/benefício. In: SIMPÓSIO DA PECUÁRIA DE CORTE, 2., 2002, Lavras. Anais... Lavras: UFLA, 2002. p. 19-42.

MACEDO, M. C. M.; KICHEL, A. N.; ZIMMER, A. H. Degradação e alternativas de recuperação de pastagens. Campo Grande: Embrapa Gado de Corte. 2000. 4 p. (Embrapa Gado de Corte. Comunicado técnico, 62).

MALAVOLTA, E.; VITTI, G. C.; OLIVEIRA, S. A. de. Avaliação do estado nutricional das plantas - princípios e aplicações. 2. ed. Piracicaba: POTAFOS, 1997. 319 p.

MELlO, A. H.; SILVA, A. S.; SANTOS, E. R. Produção de estilosantes Campo Grande inoculado com fungos micorrízicos arbusculares para a formação de banco de proteína. Enciclopédia Biosfera, Centro Científico Conhecer, Goiânia, v. 6, n. 11, p. 1-7, 2010.

MESQUITA, E. E.; FONSECA, D. M. da;
NASCIMENTO JUNIOR, D. do; PEREIRA, O. G.; PINTO, J. C. Efeitos de métodos de estabelecimento de braquiária e estilosantes e de doses de calcário, fósforo e gesso sobre alguns componentes nutricionais de forragem. Revista Brasileira de Zootecnia, Viçosa, v. 31, n. 6, p. 2186-2196. 2002.

MIYAZAWA, M.; PAVAN, M. A.; BLOCH, M. de F. Análise química de tecido vegetal. Londrina: IAPAR. 1992, 17 p. (IAPAR. Circular técnica, 74).

MOURA, R. L.; NASCIMENTO, M. P. S. C. B.; RODRIGUES, M. M.; OLIVEIRA, M. E.; LOPES, J. B. Razão folha/haste e composição bromatológica da rebrota de estilosantes Campo Grande em cinco idades de corte. Acta Scientiarum. Animal Sciences, Maringá, v. 33, n. 3, p. 249-254, 2011.

NOLLER, C. H.; NASCIMENTO JUNIOR, D.; QUEIROZ, D. S. Exigências nutricionais de animais em pastejo. In: SIMPÓSIO SOBRE MANEJO DA PASTAGEM, 13., 1996, Piracicaba. Anais... Piracicaba: Fundação de Estudos Agrários Luiz de Queiroz, 1996. p. 319-352.

NOVAIS, F. R.; SMYTH, T. J. Fósforo em solo e planta em condições tropicais. Viçosa: UFV, 1999. 399 p.

NOVAIS, R. F.; NEVES, J. C. L.; BARROS, N. F. Ensaios em ambiente controlado. In: OLIVEIRA, A. J. de; GARRIDO, W. E.; ARAUJO, J. D. de; LOURENÇO, $\mathrm{S}$. (Coord.). Métodos de pesquisa em fertilidade do solo. Brasília: EMBRAPA-SEA, 1991, p. 189-247.

OLIVEIRA, O. C.; OLIVEIRA, I. P.; FERREIRA, E.; ALVES, B. J. R.; CADISH, G.; MIRANDA, C. H. B.; VILELA, L.; BODDEY, R. M.; URQUIAGA, A. A baixa disponibilidade de nutrientes do solo como uma causa potencial da degradação de pastagens no cerrado brasileiro. In: SIMPÓSIO BRASILEIRO DE RECUPERAÇÃO DE REAS DEGRADADAS, 3., Ouro Preto, 1997. Anais... Viçosa, MG: SOBRADE/UFV, 1997. p. 110-117.

PASSOS, R. R.; FAQUIN, V.; CURI, N.; EVANGELISTA, A. R.; VILLA, M. R. Fontes de fósforo, calcário e gesso na produção de matéria seca e perfilhamento de duas gramíneas em amostras de um Latossolo ácido. Revista Brasileira de Zootecnia, Viçosa, MG, v. 26, n. 2, p. $227-$ 233, 1997.

PAUlinO, V. T.; COLOZZA, M. T.; COSTA, N. L.; OTSUK, I. P. Respostas de Stylosanthes capitata Vogel à aplicação de nutrientes e doses de calcário em solos de cerrado. In: CONGRESSO DE ZOOTECNIA SABER PRODUZIR, SABER TRANSFORMAR, ESC. SUP. AGRÁRIA CASTELO BRANCO. 16., 2006. Anais... [s.l: s.n], 2006. p. 54-62. Disponível em: <http:// 
www.nutricaodeplantas.agr.br/site/downloads/unesp jaboticabal /omissaoestilosantes.pdf $>$. Acesso em: 31 jan. 2009.

PETEAN, L. P.; TORMENA, C. A.; FIDALSKI, J.; ALVES, S. J. Altura de pastejo de aveia e azevém e qualidade física de um Latossolo Vermelho distroférrico sob integração lavoura-pecuária. Semina: Ciências Agrárias, Londrina, v. 30, p. 1009-1016, 2009. Suplemento 1 .

RAIJ, B. van. Fertilidade do solo e adubação. Piracicaba: Ceres; Potafos, 1991. 343 p.

RODRIGUES, F. A. V. Disponibilidade de cobre e zinco para mudas de eucalipto em solos de cerrado. 2009. Dissertação (Mestrado) - Universidade Federal de Viçosa. Viçosa, MG.

ROLIM NETO, F. C.; SCHAEFER, C. E. G. R.; COSTA, L. M.; CORRÊA, M. M.; FERNANDES FILHO, E. I.; IBRAIMO, M. M. Adsorção de fósforo, superfície específica e atributos mineralógicos em solos desenvolvidos de rochas vulcânicas do Alto Paranaíba (MG). Revista Brasileira de Ciência do Solo, Viçosa, MG, v. 28, n. 6, p. 953-964, 2004.

RUSSELLE, M. P. Nutrient cycling in pasture. In: SIMPÓSIO INTERNACIONAL SOBRE PRODUÇÃO ANIMAL EM PASTEJO, 1., 1997, Viçosa, MG. Anais... Viçosa, MG: Universidade Federal de Viçosa, 1997. p. 235-266.

SANTOS, F. C.; NOVAIS, R. F.; NEVES, J. C. L.; FOLONI, J. M.; ALBUQUERQUE FILHO, M. R.; KER, J. C. Produtividade e aspectos nutricionais de plantas de soja cultivadas em solos de cerrado com diferentes texturas. Revista Brasileira de Ciência do Solo, Viçosa, MG, v. 32, n. 5, p. 2015-2025, 2008.

SCHUNKE, R. M.; SILVA, J. M. da. Estilosantes Campo Grande consorciado com braquiária contribui para a sustentabilidade da pastagem. Campo Grande: Embrapa Gado de Corte, 2003. 5 p. (Embrapa Gado de Corte. Comunicado técnico, 83).

SHELTON, H. M.; FRANZEL, S.; PETERS, M. Adoption of tropical legume technology around the world: analysis of success. In: McGILLOWAY, D. A. (Ed.). Grassland: a global resource. Wageningen: Wageningen Academic Publishers, 2005. p. 149-299.

SISTEMA Brasileiro de classificação de solo. 2. ed. Rio de Janeiro: Embrapa Solos, 2006. 306 p.

VALENTIM, J. F.; ANDRADE, C .M. S. Perspectives of Grass-legume pastures for sustainable animal producdtion in the tropics. In: REUNIÃO ANNUAL DA SOCIEDADE BRASILEIRA DE ZOOTECNIA, 41., 2004, Campo Grande. Anais... Campo Grande: Sociedade
Brasileira de Zootecnia; Embrapa Gado de Corte, 2004. p. 142-154. 1 CD-ROM.

VALLADARES, G. S.; PEREIRA, M. G.; DOS ANJOS, L. H. C. Adsorção de fósforo em solos de argila de baixa atividade. Bragantia, Campinas, v. 62, n. 1, p. 111-118, 2003.

WERNER, J. C. Adubação de pastagens. Nova Odessa: Instituto de Zootecnia. 1984. 49 p. (Boletim técnico, 18). 
